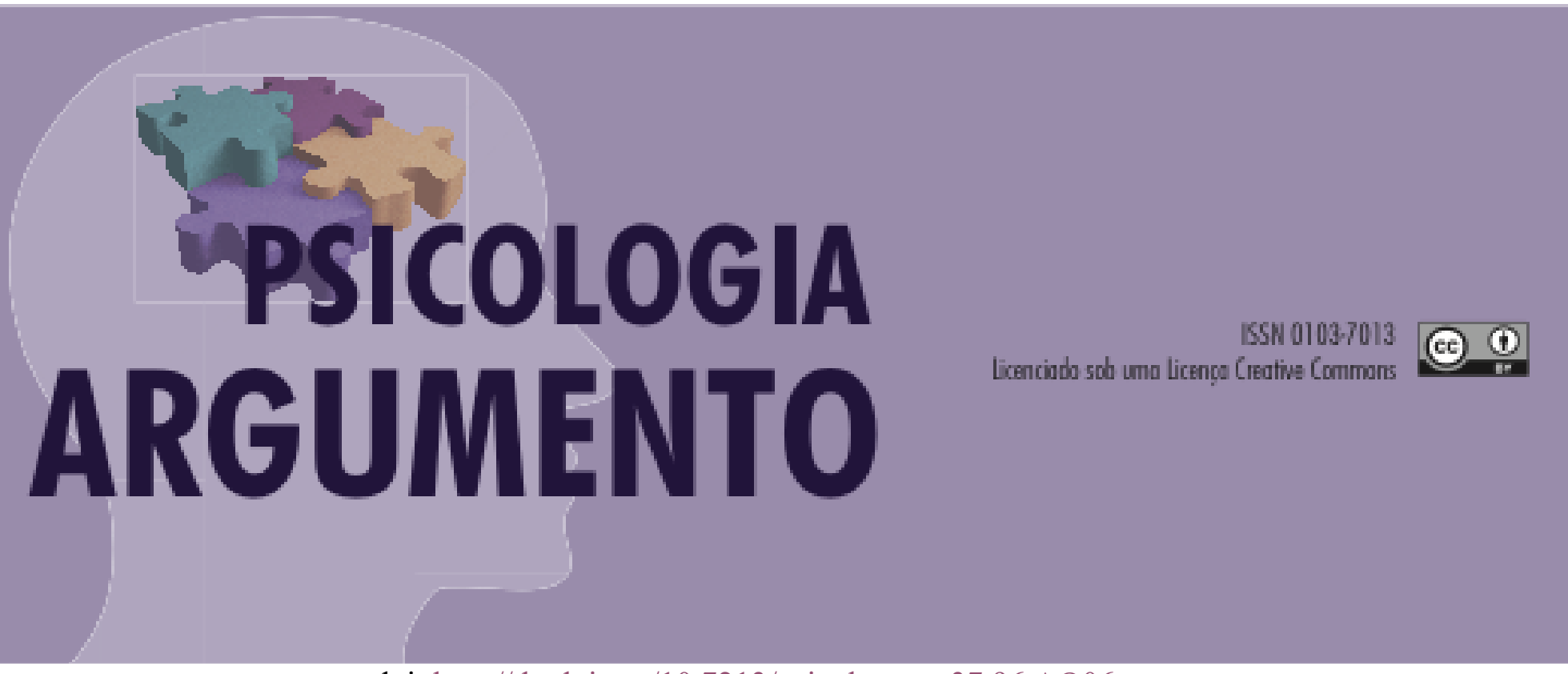

doi: http://dx.doi.org/10.7213/psicolargum.37.96.AO06

\title{
Adoção de crianças soropositivas no Brasil
}

\author{
Adoption of soropositive children in Brazil
}

Adopción de niños soropositivos en Brasil

\begin{abstract}
Alessandra Schosloski Alves Coutinho
https://orcid.org/0000-0001-6970-6843

Mestre em Psicologia pela Universidade Tuiuti do Paraná (UTP), servidora pública federal vinculada a Universidade Federal do Paraná (UFPR), e-mail: alessandrasacoutinho@gmail.com

\section{Maria Cristina Antunes \\ https://orcid.org/0000-0002-6767-518X}

Doutora em Psicologia, Docente do Mestrado em Psicologia da Universidade Tuiuti do Paraná (UTP) e pesquisadora NEPAIDS da Universidade de São Paulo (USP) e-mail: mcrisantunes@uol.com.br

Gislei Mocelin Polli

https://orcid.org/0000-0001-7254-7441

Doutora em Psicologia, Docente do Mestrado em Psicologia da Universidade Tuiuti do Paraná (UTP), email: gislei.m.polli@gmail.com
\end{abstract}

O objetivo dessa pesquisa foi analisar o processo de adoção de crianças e adolescentes HIV positivos sob a perspectiva do adotante. Trata-se de pesquisa qualitativa, realizada em diferentes localidades do território brasileiro, com participação de 10 pessoas que adotaram crianças soropositivas. Foram realizadas entrevistas a partir de um roteiro semiestruturado, sobre: dados sóciodemográficos, descrição do processo adotivo e de suas dificuldades, aspectos relacionados à preparação para a adoção, HIV, família e amigos, tratamento, cuidado, estigma e preconceito vivenciados, adaptação da criança no ambiente familiar e escolar, grupos de apoio à adoção. As 
entrevistas foram transcritas e foi realizada a análise de conteúdo. Os resultados revelaram que a morosidade processual constitui o principal entrave e deve ser repensado no âmbito das suas competências, nas diferentes instâncias. Os adotantes sugerem que o acesso às informações sobre crianças soropositivas, em condições legais de serem adotadas, seja facilitado através de mecanismos de buscas ou sistemas específicos. Os dados apontaram para a vulnerabilidade individual, social e programática das crianças soropositivas que se encontram abrigadas em nosso país. Enquanto institucionalizadas, elas se encontram atreladas à justiça e aos serviços públicos, o que requer agilização para abreviar o longo trâmite judicial, que retarda a construção de uma nova trajetória de vida. Essas crianças ficam privadas por maior tempo de estabelecer vínculos de com uma nova família, que lhe destine cuidados, amor, carinho e atenção, aspectos essenciais ao seu bom desenvolvimento.

Palavras chave: Órfãos, AIDS, HIV, Adoção.

Abstract
The objective of this research was to analyze the adoption process of HIV positive children and adolescents from the adopter perspective. This is a qualitative research, conducted in different localities of the Brazilian territory, with the participation of 10 people who adopted HIV-positive children. Interviews were conducted from a semi-structured script on: sociodemographic data, description of the adoptive process and its difficulties, aspects related to preparation for adoption, HIV, family and friends, treatment, care, stigma and prejudice experienced, child adaptation. in the family and school environment, adoption support groups. The interviews were transcribed, and content analysis was performed. The results showed that procedural delays are the main obstacle and should be rethought within the scope of their competences in the different instances. Adopters suggest that access to information about HIV-positive children, under legal conditions for adoption, be facilitated through search engines or specific systems. The data pointed to the individual, social and programmatic vulnerability of seropositive children who are sheltered in our country. While institutionalized, they are linked to justice and public services, which requires speed to shorten the long judicial process, which delays the construction of a new life trajectory. These children are deprived for the longest time of establishing bonds with a new family, destined to care, love, affection and attention, essential aspects to their good development. Keywords: Orphans, AIDS, HIV, Adoption.

\begin{abstract}
Resumen
El objetivo de esta investigación fue analizar el proceso de adopción de niños y adolescentes VIH positivos desde la perspectiva del adoptante. Esta es una investigación cualitativa, realizada en diferentes localidades del territorio brasileño, con la participación de 10 personas que adoptaron niños VIH positivos. Las entrevistas se realizaron a partir de un guion semiestructurado sobre: datos sociodemográficos, descripción del proceso de adopción y sus dificultades, aspectos relacionados con la preparación para la adopción. VIH, familiares y amigos, tratamiento, atención, estigma y prejuicio experimentado, adaptación infantil. en el entorno familiar y escolar, grupos de apoyo a la adopción. Las entrevistas fueron transcritas y se realizó un análisis de contenido. Los resultados mostraron que los retrasos en los procedimientos son el principal obstáculo y deben repensarse dentro del alcance de sus competencias en los diferentes casos. Los adoptantes sugieren que el acceso a la información sobre niños VIH positivos, bajo condiciones legales de adopción, se facilite a través de motores de búsqueda o sistemas especificos. Los datos apuntan a la vulnerabilidad individual, social y programática de los niños seropositivos que se encuentran protegidos en nuestro país. Si bien están institucionalizados, están vinculados a la justicia y los servicios públicos, lo que requiere velocidad para acortar el largo proceso judicial, lo que retrasa la construcción de una nueva trayectoria de vida. Estos niños se ven privados durante más tiempo de establecer vínculos con una nueva familia, destinados al cuidado, el amor, el afecto y la atención, aspectos esenciales para su buen desarrollo.
\end{abstract}

Palabras clave: Huérfanos, SIDA, VIH, Adopción. 


\section{Introdução}

Após quatro décadas do início da epidemia da aids, um dos seus impactos foi o aumento de crianças órfãs, pela morte de seus pais, e soropositivas, em virtude da transmissão vertical (Yarney, Mba, Asampong, 2015). As terapias antirretrovirais são eficientes para diminuir a transmissão do vírus HIV da mãe para a criança, reduzindo à menos de $2 \%$ a chance de mortalidade da criança (French, Thorne, Byrne, Cortina-Borja, Tookey, 2017), mas ainda é uma realidade presente no Brasil. Segundo Cadastro Nacional de Adoção (CNA), 4.926 crianças e adolescentes estavam aptos para adoção no Brasil em 2017, dentre os quais 106 com HIV. Em relação aos pretendentes à adoção, no mesmo ano, eram 42.158, sendo que 1.889 aceitavam crianças com HIV.

O abandono é um problema social, relacionado à população pobre e trabalhadora, que tem dificuldade de acesso às informações e aos serviços de saúde e educação (Santos, 2009). A perda dos familiares expõe a criança à angústia, à insegurança, ao medo, à solidão, à tristeza, à falta de afeto e cuidados. Dentre as crianças e adolescentes institucionalizados, é importante direcionar especial atenção para as portadoras de HIV, tendo em vista a ampliação do quadro de vulnerabilidade ao qual estão submetidas. Os órfãos da aids, além de vivenciarem o luto pela perda familiar, convivem com uma doença crônica que demanda cuidados especiais de saúde para melhorar sua sobrevida (Beegle, Weerdt e Dercon, 2007). Em geral, as crianças soropositivas enfrentam vários problemas com relação à educação, nutrição, sofrimento psicológico, estigma e discriminação (Yarney , Mba, Asampong, 2015). O desenvolvimento saudável dos filhos de pais soropositivos deve ser foco de atenção e intervenção (Ferrara, 2009; Tshweneagae, Wright e Hoffmann, 2010). As intervenções direcionadas à essas crianças e adolescentes devem estar pautadas na atenção às suas necessidades e de seus familiares, no que diz respeito à saúde, ao cuidado e ampliação da rede de apoio social (Betancourt et al. 2010, Galvão et al., 2013, Apolinário \& Antunes, 2015).

O estigma da aids é uma das principais barreiras para que se possam obter respostas eficientes nas áreas de prevenção, cuidado e serviços (Bond, Chase \& Aggelton, 2002; Kalichaman \& Simbayi, 2003; Weiss \& Ramakrisma, 2006). Como meta do UNAIDS (Joint United Nations Programon HIV/AIDS), o enfrentamento do estigma e da discriminação é identificado como ponto imperativo para o sucesso frente à epidemia HIV/aids. 
Questões relacionadas ao contexto cultural, de nacionalidade, aspectos inter e intrapessoais devem ser levados em consideração para compreensão do estigma e do preconceito sofrido por pessoas que vivem com HIV/aids (Parker \& Aggleton, 2003; Ogden \& Nyblade, 2005; Reidpath \& Chan, 2005). Para o enfrentamento dessa situação, é importante desenvolver e avaliar programas de prevenção, tratamento e intervenção em âmbitos locais e globais, como foco na redução do preconceito e do estigma direcionado às pessoas portadoras de HIV/aids (Mahajan et al., 2008).

Pessoas portadoras de HIV/aids têm sido vítimas de preconceito e discriminação desde a descoberta da doença até os dias atuais (Sadala, 2006; Garcia e Koyama, 2008). Para minimizar o sofrimento vivenciado e visando o enfrentamento e a redução do estigma e da discriminação, é fundamental a conscientização sobre essa problemática e a adoção de uma postura ética por parte dos profissionais de saúde, de assistência social, do direito e da sociedade em geral (Garcia e Koyama, 2008). Para que o preconceito possa ser reduzido, ou eliminado, é essencial que sua existência seja reconhecida, o que nem sempre é uma tarefa fácil, pois expõe uma realidade que muitas vezes a sociedade busca negar (Zucchi et al., 2010). O estigma da aids deve ser minimizado entre as crianças e seus grupos de amizade, pois parece torná-las ainda mais vulneráveis ao bullying. A exposição ao preconceito, o bullying e os maus-tratos das crianças soropositivas pelos pares e/ou pela família tem relação com o adoecimento (Cluver, Bowes, Gardner, 2010).

Com o aumento do número de crianças institucionalizadas, crescem também os desafios em escala global. Os trabalhos desenvolvidos para redução de vulnerabilidade destas crianças não devem ser diferenciados em relação às crianças portadoras de HIV, tendo em vista que isso poderia aumentar a estigmatização e o preconceito. Devem-se buscar políticas inclusivas que possam atender a todas as crianças institucionalizadas (Shetty \& Powell, 2003). A qualidade de vida deve ser melhorada, a tendência à institucionalização dos órfãos da aids deve ser evitada e a redução do estigma e da discriminação pelo HIV/aids é fundamental para a diminuição da vulnerabilidade (Doring, 2004). O estigma e o preconceito são formas de camuflar a realidade para amenizar a exposição social (Almeida e Labronici, 2007). Devemos observar que a aids trouxe consigo a intolerância, a suscetibilidade no sentir e no proceder de forma moral, além da apreensão. A vulnerabilidade está envolta por questões sociais, políticas e econômicas. Estudar esse contexto no Brasil é indispensável para a análise da situação dos adolescentes convivendo com HIV/aids (Marques et al, 2006). 
O objetivo desta pesquisa foi analisar o processo de adoção de crianças e adolescentes soropositivos sob a perspectiva do adotante. Seus objetivos específicos foram: caracterizar o perfil do adotante e da criança soropositiva; conhecer as motivações e significados deste tipo de adoção; descrever o processo adotivo; analisar os processos de estigmatização e discriminação vivenciados pela criança soropositiva e pelo adotante.

\section{Método}

Este estudo se propões a pesquisar a adoção de crianças soropositivas sob a perspectiva do adotante. A pesquisa qualitativa responde a questões específicas em realidades distintas, oportunizando a análise de justificativas, interpretações, valores, afinidades, convívio (Minayo, 1994). Assim, esta é uma pesquisa de abordagem qualitativa descritiva, em que foi utilizada a entrevista semiestruturada com análise de conteúdo. A entrevista semiestruturada possibilita maior autonomia para o relato de vivências e a apresentação de situações, por ser caracterizada por perguntas abertas que propiciam à pesquisa detalhes nas respostas.

[...] perfeitamente possível e necessário o conhecimento e utilização de análise de conteúdo enquanto procedimento de pesquisa, no âmbito de uma abordagem metodológica crítica e epistemologicamente apoiada numa concepção de ciência que reconhece o papel ativo do sujeito na produção do conhecimento. (Franco, 2012, p. 10).

\section{Participantes}

A pesquisa foi realizada com oito mulheres e dois homens que adotaram uma ou mais crianças portadoras do HIV. Todos os participantes eram de cor branca. A faixa etária do grupo pesquisado variou entre 30 a 35 anos. Os participantes moravam nos seguintes Estados: Rio de Janeiro, São Paulo, Minas Gerais, Paraná, Santa Catarina e Rio Grande do Sul. Quanto à religião, cinco pessoas eram espíritas, duas eram evangélicas, uma era católica e duas não tinham religião. Em relação à escolaridade, todos possuíam formação superior, sendo que quatro tinham pós-graduação. A renda individual variou de $\mathrm{R} \$ 3.000,00$ a $\mathrm{R} \$ 13.000,00$ e a renda familiar variou de $\mathrm{R} \$ 6.000,00$ à $\mathrm{R} \$ 60.000,00$. Todos os entrevistados tinham casa própria.

Em relação ao estado civil, seis participantes declararam que eram casados, dois solteiros, um divorciado e um com união estável. Dentre aqueles que se declararam 
solteiros e divorciados, todos alegaram que conviviam com um parceiro(a) em uma relação estável. O tempo de convivência dos casais variou entre seis a dezenove anos, sendo que dois homens e quatro mulheres encontravam-se em uma relação heterossexual e quatro mulheres em uma relação homossexual. Ao avaliarem o seu relacionamento, nove entrevistados afirmaram que a convivência era boa, sem conflitos, e apenas uma entrevistada afirmou que ocorriam brigas. Destes, quatro participantes informaram que tinham filhos biológicos.

\section{Procedimentos e Instrumentos}

Pela dificuldade de localização de participantes, foi adotada uma amostragem de conveniência, sendo que o número de entrevistados foi definido ao longo da pesquisa. Foi realizado contato com a Vara da Infância e Adolescência, porém devido os processos de destituição do poder familiar tramitarem em segredo de justiça, foi negada a realização da indicação de pessoas que tinham realizado a adoção de crianças soropositivas. Desta forma, através de indicações pessoais e utilizando uma metodologia "de bola de neve", foram realizados os contatos com pessoas que adotaram crianças com esse perfil. Optouse pelo contato por meio da rede social facebook, com grupos de apoio à adoção no Brasil. A adesão foi significativa, em razão do interesse dos grupos no tema tratado. Foram recebidas 37 indicações desses grupos de apoio de pessoas que adotaram crianças soropositivas. As pessoas indicadas foram convidadas pelas redes sociais, e-mail ou por correspondência. Aceitaram participar do estudo 10 pessoas, três se recusaram e 24 responderam à solicitação enviada. As entrevistas foram realizadas todas por Skype, tiveram duração entre 60 e 90 minutos. Todas as entrevistas foram gravadas e posteriormente transcritas na íntegra, garantindo confiabilidade dos dados.

Todos os participantes aceitaram e assinaram o Termo de Consentimento Livre e Esclarecido - TCLE. Esta pesquisa foi aprovada e autorizada pelo Comitê de Ética e após esta aprovação procedeu-se à coleta de dados.

Instrumentos e análise dos dados

Os dados foram coletados por meio de entrevista, para a qual utilizou-se um roteiro semiestruturado de perguntas. Foram abordados os seguintes temas: dados sócios demográficos com estabelecimento de perfil do adotante e da criança adotada, processo 
adotivo, estigma e preconceito vivenciados, relações com os familiares, adaptação da criança na escola e no ambiente familiar.

Foi realizada a análise do conteúdo, que segundo Franco (2012), vislumbra o delineamento mais amplo da comunicação e realizada em três fases: a descrição, a interpretação e a inferência. As respostas obtidas por meio das entrevistas semiestruturadas foram categorizadas, com o propósito de responder aos objetivos da investigação. Através deste processo de tratamento dos dados houve o reconhecimento de categorias e subcategorias de análise, verificando-se suas particularidades e com isto favorecendo a compreensão da temática relacionada. Nesta metodologia de pesquisa há a interpretação de comunicações por meio de uma descrição sistemática, a fim de compreender de forma crítica o sentido evidenciado ou subentendido em seu conteúdo. A análise realizada permitiu o estabelecimento das seguintes categorias: a) processo adotivo; b) dificuldades no processo adotivo; c) aspectos relacionados a preparação para adoção; d) HIV, família, amigos e escola; e) HIV, tratamento, cuidados e preconceito; f) HIV, grupos de apoio de adoção e Adoção Positiva.

\section{Resultados e discussão}

A análise das entrevistas demonstrou que oito entrevistados adotaram uma criança e dois entrevistados adotaram duas crianças, sendo que a maioria afirmou que tinham preferência por meninas. Entre as crianças adotadas, oito eram meninas e quatro eram meninos. Em relação à cor, cinco crianças eram brancas, quatro crianças eram pardas e duas eram negras. Como todos os adotantes eram de cor branca, conclui-se que destas adoções, seis foram inter-raciais.

No momento da adoção nove crianças tinham até três anos e três crianças tinham entre quatro e seis anos. As adoções denominadas "precoces" são as de crianças menores de três anos. Acima dessa idade já são denominadas adoções tardias. Observou-se que os adotantes entrevistados optaram por adoções precoces, confirmando que as adoções denominadas tardias são as mais difíceis de ocorrerem devido à preferência dos adotantes (Costa e Rossetti-Ferreira, 2007, Hubner e Siqueira, 2010). Em geral existe a preferência por adoções precoces, de forma que os adotantes possam acompanhar todas as etapas da vida da criança (Hubner e Siqueira, 2010). 
Em um dos casos, além de ter sido uma adoção tardia, a criança tinha problemas de locomoção em função de um quadro de paralisia cerebral. Houve uma adoção de irmãos gêmeos. Na adoção de irmãos, o ECA (Brasil, 2009) prevê que irmãos não devem ser separados, salvo em condições excepcionais. Verifica-se que os casos são analisados pela justiça e visam o comprometimento em manter os vínculos com as famílias de adotantes do mesmo Estado e Cidade nos casos em que há a separação dos irmãos (Brasil, 2009).

Um dos entrevistados relatou que adotou duas crianças, mas que foram realizados dois processos diferentes. Os pretendentes à adoção podem optar por adotar uma ou mais crianças. Os adotantes, após realizarem a primeira adoção, podem abrir outro processo ou solicitar a reabertura do mesmo processo, tudo dependerá a da orientação direcionada pela Vara da Infância e Juventude.

Significados associados à adoção.

A análise de conteúdo (quadro 1) demonstrou que na categoria significados da adoção, foram encontradas 3 subcategorias de respostas: amor, constituir uma família, realizar um sonho. Na primeira subcategoria, o amor foi citado por seis entrevistados, relacionando a adoção com um ato de amor, de entrega, de vínculo afetivo. Na segunda subcategoria, a adoção foi associada à realização de um desejo por quatro entrevistados, possibilitando o torna-se mãe. Na terceira subcategoria, a adoção foi associada à constituição de uma família, de um vínculo, à possibilidade de ter um filho.

O significado da adoção deve ser entendido como um processo em transformação, que tem elementos pessoais e coletivos (Valerio \& Lyra, 2012). A noção de família vem sofrendo constantes transformações, com novas composições familiares. O modelo de família nuclear da sociedade tradicional burguesa, monogâmica, composta por pai, mãe e filhos, vem sendo substituído por novas composições familiares (Uziel, 2007). Os casamentos por conveniência e para a manutenção do capital dentro da família, foi sendo substituído pela valorização do sentimento, do desejo, do afeto. Formar uma família passou a ter outro significado a partir do final do séc.XIX e início do séc. XX. Observase que o desejo de parentalidade continua presente. $\mathrm{O}$ significado da adoção está relacionado ao contexto social, mas principalmente à história de vida e de um desejo pessoal (Miranda e Cohen, 2012). "Assim como a gestação de um filho ocorre sob a égide de um desejo, a adoção de uma criança deve também ocorrer por meio desse prisma 
singular de encontro dos sujeitos com seu desejo.” (Oliveira, Souto, Silva-Júnior, 2017, p.915).

A adoção pode ter um significado altruísta ou hedonista, segundo Reppold e Hutz (2003). A adoção pode estar relacionada ao desejo de beneficiar a criança, como um ato de amor e doação, ou pode estar relacionada ao desejo de ter um filho. Em nosso estudo, observamos que ambos os significados estavam presentes. Adotar uma criança possibilitou a realização de um desejo, entre os entrevistados. A adoção como uma forma de realizar o desejo e de constituir uma família (ter filho) é citada por vários autores (Weber, 2004; Gondim, Crispim, Fernandes, Rosendo, Brito, Oliveira, \& Nakano, 2008; Félis \& Almeida, 2016; Araújo e Faro, 2017). A adoção como um ato afetivo, de amor, também foi descrita por vários autores (Reppold e Hutz, 2003; Oliveira, Souto, \& Silva Júnior, 2017; Araújo e Faro, 2017).

Quadro 1.

Categorias de respostas à pergunta "Qual o significado da adoção para você?".

\begin{tabular}{|l|l|l|}
\hline Categoria & Subcategoria & Indicadores \\
\hline Adoção & Amor & E2:Amor... \\
& E3: Acho principalmente um ato de amor. E de desejo também. \\
& E5: Preenchimento de uma lacuna, de um amor, filial, uma coisa \\
& assim. \\
& E8: O mesmo significado do amor incondicional \\
& E9: Amor. No início pensei em auxiliar uma criança, mudar uma \\
& história, dar uma oportunidade. Mas para mim significa amor. \\
& E10: para mim a adoção é uma forma de realização familiar \\
& desvinculada ao fator genético, para mim é a representação pura \\
& Realizar um sonho & E2: ... é a minha realização como mãe. \\
& & E6: Adoção foi o que tornou possível ser mãe. \\
& E10: um sonho realizado, é algo que verdadeiramente desejei a \\
& vida toda \\
\cline { 2 - 4 } & Constituir família & E1: Filiação. Para mim a adoção é o planejamento familiar. É... \\
& Assim como eu planejei ter meus filhos biológicos, eu planejei ter \\
& meu filho por adoção, e desde que eu me casei e desde que \\
& conheci o meu marido, nós tínhamos em mente que teríamos se \\
& possível filhos biológicos, mas que certamente fillhos por adoção. \\
& E4: Significa bem isso, ter um filho. Quando eu penso em adoção, \\
& assim, ter um filho, e adoção para mim significa isso, ter um filho. \\
& E6: Filhos. \\
& E7: Vínculos. Família. \\
\hline
\end{tabular}

\section{O processo adotivo}

Essa categoria agrupou falas dos participantes relacionadas às suas experiências em relação ao processo adotivo. Observou-se que sete participantes avaliaram de forma positiva, afirmando que o processo foi rápido e tranquilo. Com relação aos aspectos negativos, três afirmaram que foi lento, burocrático e tenso. Todos relataram que a 
destituição do poder familiar ocorreu juntamente com a adoção. Um participante informou que observou um protecionismo em relação à família biológica, o que ocasionou a demora no trâmite, não oportunizando às crianças a convivência familiar, direito este que deveria ser garantido. Em dois casos foi informado que foram realizadas habilitações específicas. Três participantes informaram que tiveram que contratar um advogado para os trâmites da adoção. O processo de adoção ainda não estava finalizado em dois casos. Todos os entrevistados relataram que durante a espera da adoção sentiram agonia, ansiedade e medo. Dados similares foram relatados por Huber e Siqueira (2010), que afirmam que a espera pela adoção é desgastante e pode acarretar em sofrimento, fantasias e questionamentos.

Em relação ao processo adotivo, observamos três tipos de situações: a) com as crianças e adolescentes, que estão disponíveis para a adoção, após as formalidades e exigências para liberação da adoção; b) as criança e adolescentes em situação indefinida, que ainda não foi destituído o poder familiar; c) os adotantes - que são submetidos à uma análise cuidadosa e criteriosa. Vale ressaltar que os serviços fazem uma análise rigorosa, visando a reintegração familiar. Preferencialmente a criança deve permanecer no seio familiar biológico, sendo encaminhado para a adoção quando se esgotam todas as possibilidades de reinserção. Com esta situação, a criança permanece institucionalizada por longos períodos e sem a possibilidade de uma família substituta pela via da adoção (Andrei, 2005, Siqueira, 2012).

A demora na adoção variou de nove meses a dois anos, mas ocorreram casos que esse período durou até 12 anos. O processo de adoção em geral é demorado (Reppold e Hultz, 2003). Nesse sentido, é pertinente descomplicar o processo de adoção e que os adotantes devem ser auxiliados durante esse período de espera (Maldonado, 1995).

Um participante informou que não existia uniformidade no processo, que variava conforme a comarca, o Estado, o Juiz e os técnicos judiciários. Alguns pesquisadores abordam essa problemática e afirmam que a obtenção de dados estatísticos pertinentes à adoção não é tarefa fácil, pois existe a questão do segredo de justiça, os problemas na forma de alimentação de dados individualizados e as falhas nos relatórios da rede de proteção (Brasil, 2013b; Lee \& Matarazzo, 2001; Silveira, 2005).

Dois entrevistados afirmaram que obtiveram a guarda provisória em caráter de urgência devido à problemas de saúde da criança. Estes casos estão amparados pela Lei $n^{\circ} 12.955 / 2014$, que estabelece a prioridade de tramitação dos processos de adoção em 
casos que o adotando for uma criança ou adolescente com deficiência ou com doença crônica. Nas demais adoções, não foi dada prioridade alguma, mesmo havendo situações de risco eminente e adoecimento grave. Apesar de existir uma lei específica para a adoção, observa-se que ela não está sendo colocada totalmente em prática, pois essas crianças teriam prioridade absoluta nos processos de adoção. Segundo Bochnia (2010), os órgãos competentes que devem cuidar e zelar das crianças institucionalizadas não cumprem o princípio de prioridade absoluta e o trâmite legal preferencial. Uma revisão de literatura (Apolinário \& Antunes, 2015) demonstrou inúmeras dificuldades enfrentadas por essas crianças: a orfandade, a institucionalização, o abandono, o preconceito e a estigmatização da sociedade. Mesmo frente a tantas dificuldades, a adoção é uma possibilidade real delas terem o seu direito à convivência familiar garantido (Brasil, 2013b).

Com relação à forma de localização da criança, ela se deu da seguinte maneira: busca ativa de grupos de apoio de adoção em quatro adoções; conhecer a criança em instituição ou abrigo e solicitar adoção por encantamento com a criança em uma adoção; e contato da vara por indicação ou consulta em cinco adoções, que é o procedimento padrão. Os grupos de apoio à adoção, em parceria com as Varas da Infância, realizam buscas entre adotante previamente e regularmente habilitados. Essas buscas ativas geralmente são de crianças com necessidades específicas e que estão com dificuldade de colocação em famílias adotivas, ou seja, se enquadram nesse perfil grupos de irmãos que não devem ser separados, crianças acima de 5 anos, com deficiências físicas e ou mentais e crianças portadoras do HIV (Oliveira, 2014).

\section{Dificuldades no processo adotivo}

Durante as entrevistas, um participante relatou um grave erro judicial, em que foi efetuada a devolução de duas crianças para a família biológica, acarretando na revitimização das mesmas. Elas sofreram maus tratos e foi relatada a suspeita de abuso sexual realizado por um membro da família biológica. Esse fato ocorreu principalmente pela morosidade do processo judicial e também porque a destituição do poder familiar ainda não tinha sido realizada. Segundo Bochnia (2010), o processo adotivo não pode conter irregularidades e atos que transgridam os direitos de adotantes e adotados. Os processos judiciais não podem ser prolongados por anos. Os dados indicam que cerca de $50 \%$ das crianças institucionalizadas não tem o seu processo de destituição concluso nas 
Varas Judiciais, ou seja, ficam aguardando por longos períodos uma decisão judicial para a destituição do poder familiar e pela adoção, o que configura uma privação do direito de convivência familiar. Isso acarreta o aumento do tempo de institucionalização e a diminuição das chances de adoção e reinserção em uma nova família. A espera para a adoção, tanto dos adotantes como das crianças, é longa devido aos entraves burocráticos, procedimentos legais e ineficiência dos órgãos da rede de proteção. A demora pode acarretar na desistência do processo adotivo. A não regularização da destituição de poder familiar acarreta na permanência destas crianças em abrigos e instituições de abrigamento até os 18 anos, o que dificulta a esses indivíduos a possibilidade de inserção em seio familiar (Brasil, 2013a, 2013b). Com relação ao protecionismo da família biológica, Maldonado (1995) afirma que existe ainda a supervalorização dos laços biológicos que dificulta ainda mais o processo adotivo, tornando-o mais moroso e não oportunizando o interesse da criança.

Os entrevistados relataram as dificuldades encontradas no processo de adoção: morosidade em três entrevistas, demora no registro definitivo em duas entrevistas, burocracia em duas entrevistas, desinformação em ordens gerais e falta de informações pertinentes ao histórico da criança em quatro entrevistas, falta de profissionais para desenvolvimento de atividades nas Varas da Infância em uma entrevista e suporte insuficiente da Vara da Infância em três entrevistas e ainda protecionismo da família biológica em uma entrevista. A demora judicial é um dos principais problemas, além da discrepância entre o perfil desejado pelos adotantes e das crianças disponibilizadas para a adoção. A desinformação sobre o histórico da criança dificulta o processo de adaptação da criança. Segundo Levinzon (2014), os pais adotivos devem ter conhecimento de tudo que é pertinente a seu filho, peculiaridades, problemas, dificuldades, comportamento e histórico de vida, para melhor conhecer os problemas enfrentados e ter todo o suporte da Vara da Infância com equipe multiprofissional até a sua total adaptação.

A falta de profissionais para desenvolvimento de atividades nas Varas da Infância e o suporte inadequado demonstram a fragilidade do sistema da rede de proteção. Inúmeras falhas são apontadas por Oliveira (2014) e Silveira (2005), entre elas: erros cometidos pelos órgãos de apoio, falta de pessoas qualificadas, frágil capacitação de servidores da área judiciária, defensores e juízes despreparados (pela baixa capacitação dos advogados para lidar com situações de abuso e violência contra criança) e falta de políticas que resguardem o interesse das crianças e adolescentes. A ineficiência do 
Cadastro Nacional de adoção, bem como a sua alimentação, serve apenas para marginalizar os integrantes do processo, sejam adotantes ou adotados. A literatura aponta que a ausência de dados anteriores sobre a criança, podem causar uma falsa realidade pois são de total importância para a saúde e bem-estar da criança, bem como para a criação de vínculos e resgate de origens (Andrei, 2001; Silveira, 2005).

Aspectos relacionados a preparação para adoção

Dentre os participantes, apenas três não realizaram curso de preparação para adoção. Contudo a nova lei da adoção estabelece a necessidade de preparação dos pretendentes à adoção. Este trabalho geralmente é realizado em conjunto com grupos de apoio à adoção e a Vara da Infầncia, com a finalidade de informar detalhes gerais sobre a lei e procedimentos (Brasil, 2009; Levinzon, 2014; Faleiros \& Moraes, 2015). A preparação para postulantes à adoção visa a orientação e o atendimento da etapa necessária à habilitação para inserção no Cadastro Nacional de Adoção. Neste contexto, os grupos de apoio à adoção são parceiros do judiciário para processos seguros e concisos (Oliveira, 2014; Souza \& Casanova, 2014). É importante realizar a preparação dos pretendentes à adoção, contemplando aspectos psicossociais, jurídicos, culturais, educativos e psicológicos, tais como os medos, angústias e expectativas (Yamaoka, 2009; Silva, 2010).

Aqueles que realizaram o curso de preparação, afirmaram que receberam apenas as informações básicas sobre o processo de adoção. Todos os entrevistados relataram que não receberam informações detalhadas sobre a adoção de crianças soropositivas, ficando sob sua própria responsabilidade a aquisição de conhecimentos específicos sobre adoção e sobre o HIV e a aids. Quatro entrevistados obtiveram informações com grupos virtuais de apoio à adoção no Orkut e no Facebook, que possibilitaram a troca de experiências com outros adotantes que vivenciaram a mesma situação.

"E2: Eu acho que o Orkut me preparou muito. O contato com o grupo de apoio virtual na época do Orkut, que continua agora no Facebook, me ajudou muito, me instrumentalizou muito. Me ajudou a entender. Me ajudou a saber do processo jurídico como acontece. Me ajudou a saber o perfil real das crianças que existem para adoção. Me ajudou a entender que o judiciário tem um monte de coisas para dar conta e que adotante não é prioridade mesmo, a gente não é tratada a pão de ló, a gente não é prioridade. Existe a prioridade da criança e acho corretíssima, mas, enfim, muitas coisas que a gente fantasia antes de entrar para o mundo da adoção, eu consegui esclarecer no grupo virtual." 
Similar ao relato desses entrevistados, a literatura da área afirma os grupos de apoio à adoção (GAA) auxiliam os adotantes na fase pré-adotiva e pós-adotiva, com a troca de experiências, palestras e orientação de voluntários, de pais adotivos, de adotantes em estágio de convivência e de profissionais especializados (Oliveira, 2014; Souza, 2012; Souza \& Casanova, 2014).

Dois participantes informaram que criaram grupos de apoio de adoção, com o objetivo de disponibilizar informações que não eram encontradas em outros locais. Quatro entrevistados participavam de grupos de apoio à adoção, para trocarem experiências e auxiliarem outros pretendentes. Observou-se que esses GAA estão desempenhando algumas funções que o sistema judiciário deveria cumprir, fornecendo informações, preparando e acompanhando os pretendentes à adoção.

Com relação ao período de pós-adoção, quatro entrevistados afirmaram que participaram de grupos de apoio e em apenas um caso a Vara da Infância fez o acompanhamento pós-adoção. Os pais e as mães adotivos deveriam ser acompanhados durante todo o processo adotivo, recebendo o suporte necessário e essencial para o sucesso da adoção. A participação em grupos antes e após a adoção é fundamental para que os casais adotantes compartilhem as dificuldades e sentimentos vivenciados (Huber e Siqueira, 2010).

HIV, família, amigos e escola

Através da análise das entrevistas observou-se que oito entrevistados informaram que seus amigos mais próximos sabiam da adoção da criança com HIV, e dois afirmaram que os amigos não sabiam, pois tiveram medo que a criança sofresse discriminação e preconceito. Segundo Souza e Casanova (2014), o preconceito em geral ocorre em contextos relacionais mais próximos, entre familiares e amigos. Cabe aos pais adotivos orientarem os filhos para o desenvolvimento da autoestima e da confiança, para a aquisição de informação, para proporcionar segurança e para prepara-los para a superação desses conflitos.

"E1: Você falou a palavra certa! Preconceito. Não sabem, são poucas as pessoas que sabem que a Nina foi exposta ao HIV, exatamente pelo preconceito. É eu não vou expor minha filha, talvez se ela não tivesse negativado, eu falaria na escola, eu falaria em lugares extremamente essenciais. Mas eu não andaria com a plaquinha no peito não, assim como ela não anda com a plaquinha dizendo que é adotada. Eu não, eu não andaria com a plaquinha no peito que ela é positiva. Porque você não vê ninguém com a plaquinha que você é diabética, de que é asmática, de que é hipertensa, porque eu teria que andar com a 
plaquinha se ela fosse positiva? Eu não acredito que seja necessário, não. Mas de toda maneira alguns amigos, mais próximos sabiam da condição dela, de exposta ao HIV e os familiares também. Eles sabiam que nós estávamos abertos para a adoção positiva. Então eles imaginavam que por ela ser um bebê, branca, lá no Rio de Janeiro, alguma coisa de errado tinha. Então alguns chegavam diretamente e perguntavam se ela tinha algum problema de saúde e a gente nunca negou, não para quem perguntou, a gente fala que ela era exposta ao HIV."

Quatro participantes informaram que, se necessário, falariam para a escola que a criança tinha o HIV. Porém, observou-se que foi no ambiente escolar que os entrevistados relataram situações de preconceito, quando a situação de saúde da criança foi informada: reação de medo em uma entrevista, em outras duas entrevistas as pessoas viram o lado social da adoção e encorajaram a atitude dos pais.

Um dos entrevistados afirmou que seus amigos questionaram a razão de adotar uma criança soropositiva e disseram que nunca fariam isso, tentando justificar suas escolhas. Segundo Silva, Alvarenga \& Dupas (2014), a revelação sobre a soropositividade da criança em geral é realizada para os familiares e seguida de apoio dos mesmos. Em outros casos, a omissão ocorre por medo do preconceito, do desamparo e da rejeição.

Com relação à revelação da soropositividade para a família, oito entrevistados afirmaram que tinham contado e apenas dois revelaram apenas para os mais próximos. Com relação à reação dos familiares, três deles afirmaram que foi bem recebida, mas quatro deles disseram que os familiares tinham receio que isso pudesse causar sofrimento para a criança. Um dos entrevistados afirmou que a família reagiu de forma preconceituosa, questionando se realmente precisava adotar uma criança soropositiva. Um dos participantes disse que revelou apenas para a família de um dos adotantes, pois tinham receio sobre a receptividade da família do pai adotivo. Em um caso, o entrevistado afirmou que optaram por apresentar a criança para a família e somente depois disso é que informaram o estado de saúde da criança, como forma de dirimir o preconceito.

HIV, tratamento, cuidados e preconceito

Observou-se que seis entrevistados relacionaram a aids a algo negativo, como a morte e doença; três entrevistados associaram a aids aos tratamentos e cuidados especiais; outros dois entrevistados relacionaram ao preconceito e desconhecimento sobre a aids. 
"E4: [...] a aids ainda tem um peso enorme, difícil, ainda se associa realmente a uma doença de morte, uma doença de horror. Acho que esse nome tem um peso muito grande [...] eu uso o termo "positivo", HIV positivo mais do que a palavra aids, que para mim ainda tem um peso muito ruim por conta do histórico horrível da doença, da praga que foi."

"E10: Eu tenho uma relação de distanciamento com esse termo aids. Me remete aos anos 80 e me lembra de um período triste em que muitas pessoas morreram. Algo sem controle, era desesperador. Não imagino a angústia que deve ter sido para essas pessoas quando ainda não havia tratamento, mas então me conforto pois penso que hoje essa é uma realidade distante, ah é?!!!!!! Nessa época ter aids era morrer e pronto! Horrível. Talvez por isso eu não pense em aids. Meus filhos são portadores do HIV+, não possuem a doença, estão saudáveis e vou batalhar para que continuem assim."

Os entrevistados informaram que as dificuldades com relação a ser pai ou mãe de uma criança soropositiva eram: os exames de rotina, a expectativa de negativação, os cuidados diferenciados sem apoio familiar, o receio e o medo do futuro, o sentimento de diferença, o preconceito, a desinformação das pessoas sobre o HIV, as privações, a morosidade do SUS e a exigência de uma logística adequada.

Apenas um entrevistado informou que sofreu preconceito com olhares e culpabilização pelo contágio da criança. Já com relação às crianças, quatro adotantes afirmaram que elas passaram por situações em que sofreram preconceito. Dois entrevistados relataram que o convênio médico não queria aceitar a inclusão da criança e não estavam realizando exames de rotina, o que acarretou ações judiciais para o cumprimento de seus direitos. Em outras duas situações, foram relatadas situações ocorridas no ambiente escolar e na socialização com outras crianças, pois foi informado aos pais que as outras crianças não desejavam ter contato com uma criança soropositiva, abraçando-a ou beijando-a. Um dos entrevistados relatou que a criança sofreu um pequeno acidente e que observou-se um exagero nos procedimentos, ocasionando a exposição da criança.

Os entrevistados informaram que também sofriam preconceito devido à adoção. Um deles relatou que a família tratava de forma diferenciada o filho biológico e o filho adotivo. Dois participantes relataram que a família fazia comentário pejorativos em relação à criança e à adoção. Dois entrevistados relataram que sofriam preconceito porque as adoções eram inter-raciais e observavam o preconceito relacionado às características físicas dos pais e das crianças. Um dos adotantes relatou uma situação em que os colegas da escola tratavam a criança de forma diferenciada. 
"E6: O preconceito está dentro da gente, né. Que na verdade as crianças são iguais às outras crianças. Que a gente é melhor sem preconceito. Quando a gente espera muito, temos que fazer a nossa parte contra a discriminação que é muito forte."

Perante as situações de preconceito, seis entrevistados relataram que procuraram defender seus filhos; dois afirmaram que responderiam com a verdade; um deles pedia para não julgar a situação pois não era parte integrante da família; dois entrevistados afirmaram que retiraram essas pessoas de sua rede de convívio; um deles disse que deu informações pertinentes ao assunto, de forma a resolver a situação.

"E10: Eu geralmente fico perplexa. Já perdi a chance de dizer coisas importantes, por não ter reação imediata. Depende o caso, se for de alguma situação irrelevante, eu ignoro. Quando falam com preconceito sobre a adoção, eu sempre rebato. Rebato imediatamente! Faz tempo que não ouço comentários sobre isso. Quando ouvia, respondia sempre com informação. Já soube de comentários de terceiros. Por exemplo, meus filhos brincam muito com o filho da vizinha. Certo dia, a vizinha nos comenta que a sogra ficou chocada por ela deixar o filho dela brincar com os nossos, que era perigoso. Quando soube disso, fiquei muito irritada. Mas não estava presente na hora para responder, só soube depois. A vizinha deu conta do recado, defendeu a situação em nosso lugar. Nossa, é horrível. Fico fervendo de raiva de imaginar meus filhos sendo evitados por algum desses motivos, por hora não aconteceu."

Silva e Cavalcante (2012) ressaltam a problemática que é a aceitação de acolher uma criança soropositiva, sendo o preconceito o principal motivo (Andrei, 2005). O preconceito e a discriminação são fatores excludentes que prejudicam e diminuem a chance de adoção, em função: da idade avançada da criança, da adoção de irmãos, da adoção inter-racial, de doenças crônicas, do HIV e/ou de síndromes. Para dirimir o preconceito é necessário informação e preparação (Alves, 2010; Mignoli, Rafael \& Medeiros, 2010; Souza, 2012; Souza e Casanova, 2014). É necessário desmistificar o preconceito, orientar a população e, principalmente, realizar mais estudos específícos sobre o assunto (Mignoli, Rafael \& Medeiros, 2010).

Todos os participantes informaram que as crianças naquele momento estavam bem de saúde. As crianças HIV positivas estavam assintomáticas e respondiam de maneira positiva ao tratamento, tendo a sua carga viral controlada.

HIV, grupos de apoio de adoção e Adoção Positiva

Os grupos de apoio à adoção e as redes sociais foram as ferramentas que esses pais e mães utilizaram para buscar mais informações sobre a soropositividade na infância 
e para trocar experiências e vivências. O papel dos grupos de apoio à Adoção Positiva é fundamental para a disseminação de informações.

Segundo um dos entrevistados, é uma "Adoção Positiva".

"E4: [...] o nosso maior desafio é vencer o preconceito, porque as pessoas ainda têm muita desinformação sobre a doença, então eu acho que a adoção positiva é um belo nome para ajudar nessa batalha de luta contra o preconceito."

"E1: Acredito que seja muito importante, que os grupos de apoio à adoção fazerem este trabalho de conscientização, mas não no intuito de focar na negativação, mas sim na aceitação da doença, de entender como funciona a doença, como é o tratamento, como funciona o HIV, que hoje é está no patamar de uma doença crônica, né, para que estas adoções possam ser conscientes e não somente para andar mais rápido na fila."

Um dos entrevistados enfatizou a importância de as pessoas superarem seus preconceitos e se disporem a adotar crianças soropositivas.

"Tiveram os desafios, mas eu acho que, independentemente de qualquer característica que a criança possa apresentar quando a gente abre espaço para conhecer aquela pessoa, isso faz diferença. Eu acho que quando a gente fica preso aos conceitos e preconceitos, sejam eles quais forem, a gente às vezes perde oportunidades maravilhosas de vivenciar coisas lindas. Então eu acho que é normal, eu acho que o mais importante é ter essa ligação, fazer sentido de alguma maneira, ter o coração aberto para conhecer a criança. Eu acho que isso faz diferença." (SIC E02)

\section{Considerações finais}

Tendo como base os objetivos que nortearam esta pesquisa, observou-se os significados atribuídos à adoção foram o amor, a constituição de uma família e a realização de um sonho. Observou-se que a maioria afirmou que o processo adotivo foi tranquilo, mas em alguns casos foi lento e burocrático. O trâmite processual precisa ser repensado, especialmente no caso de crianças soropositivas, que estão em situação de vulnerabilidade, e que tem prioridade segundo a legislação.

Os adotantes devem ter acesso às informações e ter acesso facilitado para a busca pelo seu filho com acesso a mecanismos de busca e sistemas. Os casos em que ocorreu falha processual não devem ser a regra e sim a exceção. O melhor interesse da criança deve ser preconizado, pois o que observamos são crianças inseridas em instituições, sem a possibilidade de inserção familiar e sem voz para tal reclamação. A vulnerabilidade 
dessas crianças deve ser observada em todos os sentidos, seja no abandono de seus pais, seja no abandono institucional e no abandono judicial. O processo adotivo por si só é complexo, tem singularidades, subjetividades, porém deve ser repensado para atender as crianças que estão institucionalizadas em busca de um lar, não um lar substituto, mas um lar definitivo, com pessoas que amem, respeitem, zelem e cuidem.

Uma revisão de literatura realizada demonstrou que existe um número maior de artigos estrangeiros do que nacionais (Apolinário \& Antunes, 2015). No Brasil, os órfãos da aids, sob o aspecto da adoção, são uma população pouco estudada, haja visto que temos poucos artigos, bem como poucos dados oficiais sobre o fenômeno. Oliveira e Takahashi (2011) reiteram a importância de se obter e disponibilizar dados, pois dessa forma poderá ser feito um dimensionamento da problemática no Brasil e com isto desenvolver e programar políticas públicas para essa demanda em diversas áreas.

Pensar nas necessidades e carências desses órfãos possibilitará agirmos previamente de forma a romper o ciclo da orfandade e proporcionar a construção de um novo cenário para essas crianças. Devem ser criadas novas possibilidades, de forma a reinseri-los de forma mais efetiva na sociedade e na família. Mas para isso ocorrer, é necessário ampliar as casas de apoio e incrementar as políticas sociais através de programas que viabilizem condições dignas e humanas de vida para esses sujeitos e suas famílias, sejam essas adotivas ou biológicas (Abadia-Barrero, 2002; França-Junior, 2006; França-Junior, Doring, \& Stella, 2006; Kumar, 2012).

Os grupos de apoio à adoção e as Varas da Infância e Juventude devem trabalhar em conjunto, com o objetivo de propor intervenções para fornecer informações sobre a aids e as formas de cuidado, compartilhar a experiência de casos similares de adoção, trabalhar o preconceito e a discriminação com relação à soropositividade, de forma a sensibilizar um maior número de famílias para esse tipo de adoção. A escassa literatura sobre o tema é outro fator importante, sendo fundamental o desenvolvimento de novas pesquisas sobre o simbolismo da aids, do adoecimento, dos aspectos de saúde física e mental de crianças portadoras do HIV, de forma a diminuir a sua vulnerabilidade individual, social e programática, e incrementar a sua qualidade de vida e a possibilidade de reestabelecer o seu convívio familiar.

Os adotantes devem ser preparados adequadamente para efetuarem a adoção de uma criança, especialmente no que concerne ao histórico de seu futuro filho, sem omissões. Os cursos de preparação pré e pós adoção são necessários, previstos em lei, 
mas incipientes. Observam-se graves falhas na preparação dessas famílias, no acompanhamento e no auxílio das autoridades de competência. Também existem graves falhas no registro de informações acerca da criança. O acesso ao histórico da criança poderia minimizar as dificuldades de adaptação e inclusive melhoria da qualidade de vida, especialmente para as crianças soropositivas.

Os adotantes, em suas narrativas, sugerem que o acesso às informações sobre crianças soropositivas, em condições legais de serem adotadas, seja facilitado através da disponibilização de mecanismos de buscas ou sistemas específicos. Os dados extraídos da pesquisa apontaram para a existência de uma vulnerabilidade individual, social e programática em que estão imersas as crianças soropositivas que se encontram abrigadas em nosso país. Enquanto institucionalizadas, elas se encontram atreladas à justiça e aos serviços públicos, o que requer agilização para abreviar o longo trâmite que, na contramão da justiça, retarda a construção de uma nova trajetória de vida, tanto para os pretendentes à adoção, quanto para as crianças que por mais tempo ficam privadas de estabelecerem vínculos de afetividade com uma nova família, que lhe destinem cuidados, amor, carinho e atenção, aspectos essenciais ao seu bom desenvolvimento.

Pensar nas necessidades e carências dessas crianças e adolescentes soropositivos institucionalizados possibilitará agirmos previamente, de forma a romper o ciclo da orfandade e proporcionar a construção de um novo cenário, enfatizando a criação de programas assistenciais, tais como apadrinhamento afetivo, família acolhedoras e outros, que proporcionem às crianças e adolescentes a oportunidade de inserção familiar. Esses sujeitos de direitos devem ter novas possibilidades, tanto na sociedade e na família. Esses programas devem buscar condições dignas e humanas de vida para as crianças e adolescentes soropositivos.

Este estudo se limitou à vivência dos adotantes. A adoção de crianças soropositivas precisa ser aprofundada, no sentido de investigar a vivência da criança que convive com o HIV, com o abandono e com a institucionalização. Também devem ser realizadas pesquisas com adotantes que não aceitam a Adoção Positiva, de forma a aprofundar os seus olhares e dar subsídios para o desenvolvimento de intervenções com os postulantes à adoção. Sugere-se ainda a realização de pesquisas na área de institucionalização e acolhimento, de forma a avaliar esses serviços e quanto ao cumprimento de seu papel, sua eficiência no acolhimento e reinserção familiar, suas necessidades e fragilidades. Ainda carece de pesquisa a área judicial e processual seu 
trabalho, falhas, problemas, soluções, aplicações e sistemas e mecanismos de busca e processo eletrônico e físico. O desenvolvimento de pesquisas nessa área, certamente contribuirão com a minimização da vulnerabilidade dos órfãos da aids.

\section{Referências}

Abadia-Barrero, C.E. (2002) Crianças vivendo com HIV e Casas de Apoio em São Paulo: cultura, experiências e contexto domiciliar. Interface- Comunicação, Saúde, Educação; 6(11), 55-70. http://dx.doi.org/10.1590/S1414-32832002000200005

Almeida, M.R.C.B., \& Labrocini, L.M. (2007) A trajetória silenciosa de pessoas portadoras do HIV contadas pela história oral. Ciência de Saúde Coletiva, 12(12), 263274. http://dx.doi.org/10.1590/S1413-81232007000100030

Alves, G.F. (2010) Discriminação positiva para adoção de crianças institucionalizada estudos preliminares. XXIII Congresso Brasileiro das Associações Brasileiras de Magistrados, Promotores e Defensores Públicos da Infância e Juventude, no Centro de Convenções Ulisses Guimarães, Brasília - DF. Disponível em: http:/cerizzedonadel.com.br/upload/Publicacao_01-01-2012-19-02-19_.pdf

Andrei, D.C. (2005) Reencontro com a esperança: reflexões sobre adoção e família. Londrina: ABDR.

Apolinário, A.S.A.C, Antunes, M.C. (2015) Adoção de crianças e adolescentes soropositivos. Bol. - Acad. Paul. Psicol. 35(89), p. 325-349, jul. 2015 Disponível em http://pepsic.bvsalud.org/scielo.php?script=sci_arttext\&pid=S1415711X2015000200006\&lng=pt\&nrm=iso

Araujo, A.I.S., \& Faro, A. (2017). Motivações, dificuldades e expectativas acerca da adoção: perspectivas de futuros pais adotivos. Psicologia em Revista, 23(3), 790810. https://dx.doi.org/10.5752/P.1678-9563.2017v23n3p790-810

Beegle, K., Weerdt, J., \& Dercon, S. (2007). The long-run impact of orphanhood. Policy Research Working Paper, 4353. Disponível em: http://economics.ouls.ox.ac.uk/12061/

Betancourt, T. S., Fawzi, M. K. S., Bruderlein, C., Desmond, C., \& Kim, J. Y. (2010) Children affected by HIV/AIDS: SAFE, a model for promoting their security, health, and development. Psychology, Health \& Medicine, 15(3), 243-265. https://doi.org/10.1080/13548501003623997

Bochnia, S.F.(2010) Da adoção: Categorias, paradigmas e práticas do direito de família. Curitiba: Juruá.

Bond, V; Chase, E; Aggleton, P (2002) Stigma, HIV/aids prevention, and mother to child transmission in Zambia. Evaluation and Program Planning, 25, 242-356. https://doi.org/10.1016/S0149-7189(02)00046-0

Brasil (2009) Lei $n^{\circ} 12.010$, de 03 de agosto de 2009. Dispõe sobre adoção; altera as Leis nos 8.069, de 13 de julho de 1990 - Estatuto da Criança e do Adolescente, 8.560, de 29 de dezembro de 1992; revoga dispositivos da Lei no 10.406, de 10 de janeiro de 
2002 - Código Civil, e da Consolidação das Leis do Trabalho - CLT, aprovada pelo Decreto-Lei no 5.452, de 1o de maio de 1943; e dá outras providências.

Brasil, Conselho Nacional de Justiça (2013a) Encontros e desencontros da Adoção no Brasil: uma análise do Cadastro Nacional de Adoção do Conselho Nacional de Justiça (CNJ). 2013b. Retirado de: http://www.cnj.jus.br/images/pesquisasjudiciarias/Publicacoes/pesq_adocao_brasil.pdf

Brasil, Senado Federal. (2013b) Adoção: Mudar um destino. Senado busca melhorias na legislação para superar desafio de dar uma família a milhares de crianças que vivem em abrigos. Revista de audiências públicas do Senado Federal, 4(15). Retirado de: http://www.senado.gov.br/noticias/jornal/emdiscussao/Upload/201302\%20$\% 20 \mathrm{maio} / \mathrm{pdf} / \mathrm{em} \% 20 \mathrm{discuss} \% \mathrm{C} 3 \% \mathrm{~A} 3 \mathrm{o}$ !_maio_2013_internet.pdf

Cluver, L; Bowes, L ; Gardner, F (2010) Risk and protective factors for bullying victimization among aids-affected and vulnerable children in South Africa. Child Abuse \& Neglect, 34(1) , p. 793-803 https://doi.org/10.1016/j.chiabu.2010.04.002

Costa, N.R Do A; Rossetti-Ferreira, M.C. (2007) Tornar-se Pai e Mãe em um Processo de Adoção Tardia. Psicologia: Reflexão e Crítica, 20(3), 425-434, 2007. http://dx.doi.org/10.1590/S0102-79722007000300010

Doring, G, M. (2004). Situação dos órfãos em decorrência da aids em Porto Alegre/RS e fatores associados à institucionalização. Tese de doutorado. São Paulo: USP.

Faleiros, V.; Moraes, P. (2015) Desafios e possibilidades na adoção. Serviço Social \& Saúde, 13(1), 29-46. https://doi.org/10.20396/sss.v13i1.8634913

Félis, K.C., \& Almeida, R.J. (2016). Perspectiva de casais em relação à infertilidade e reprodução assistida: uma revisão sistemática / Perspective of couples about assisted reproduction and infertility: a systematic review. Reprod. Clim, 31(2), 105-111. http://dx.doi.org/10.1016/j.recli.2016.01.004

Ferrara, A. P. (2009). Orfandade e estigma: vivências de jovens órfãos em decorrência da aids. Dissertação de Mestrado. Universidade de São Paulo, São Paulo, Brasil. Disponível em: http://www.teses.usp.br/teses/disponiveis/6/6136/tde-29092009105839/publico/AndreaFerrara.pdf

França-Junior, I., Doring, M., \& Stella, I. M. (2006). Crianças órfãs e vulneráveis pelo HIV no Brasil: onde estamos e para onde vamos. Revista Saúde Pública, 40, 23-30. http://dx.doi.org/10.1590/S0034-89102006000800005

França-Junior, I. (2006) Estigma e discriminação relacionados ao HIV/aids: impactos da epidemia em crianças e jovens na cidade de São Paulo. FAPESP.

Franco, M.L.P.B. (2012) Análise de Conteúdo. Brasília, DF: Líber Livros.

French, C.E., Thorne, C., Byrne, L., Cortina-Borja, M,. Tookey, P.A. (2017). Presentation for care and antenatal management of HIV in the UK, 2009-2014. HIV Med. 18(Suppl 3):161-70. https://doi.org/10.1111/hiv.12410

Galvão, M. T. G., Cunha, G. H. Da, Rodrigues, N. L. De C., \& Gir, E. (2013) Aspectos das interações sociais de crianças portadoras de HIV pela ótica dos seus cuidadores. Revista da Rede de Enfermagem do Nordeste - Rev. Rene, 14(2). http://dx.doi.org/10.15253/rev\%20rene.v14i2.3371 
Garcia, S; Koyama, M. A. H (2008) Estigma, discriminação e HIV/aids no contexto brasileiro, 1998 e 2005. Rev. Saúde Pública [online]. ,42(suppl.1), 72-83. http://dx.doi.org/10.1590/S0034-89102008000800010

Gondim, A.K, Crispim, C.S., Fernandes, F.H.T., Rosendo, J.C., Brito, T.M.C., Oliveira, U.B., \& Nakano, T.C. (2008). Motivação dos pais para a prática da adoção. Boletim de Psicologia, 58(129), 161-170. Disponível em: http://pepsic.bvsalud.org/scielo.php?script=sci_arttext\&pid=S000659432008000200004\&lng=pt\&tlng=pt.

Hubner, M.Z.; Siqueira, A.C. (2010). Pais Por Adoção: a adoção na perspectiva dos casais em fila de espera. Psicologia: Teoria e Prática, v. 12, n. 2, 200-216. Disponível em: http://pepsic.bvsalud.org/scielo.php?script=sci_arttext\&pid=S151636872010000200014

Kalichman, S.C; Simbayi, L (2003) HIV testing attitudes, aids stigma, and voluntary counseling and testing in black township in Cape Town, South Africa. Sexually Transmitted Infections, 79, p. 442-447. http://dx.doi.org/10.1136/sti.79.6.442

Kumar, A. Aids (2012) Orphans and Vulnerable Children in India: Problems, Prospects, and Concerns. Social Work Public Health, 27(3), 205-212 https://doi.org/10.1080/19371918.2010.525136

Lee, F.I. ;Matarazzo, E.B. (2001) Prevalência de adoção intra e extrafamiliar em amostras clínica e não clínica de crianças e adolescentes. Revista Brasileira de Psiquiatria, 23(3), 149-55. http://dx.doi.org/10.1590/S1516-44462001000300007

Levinzon, G. H. (2014) Tornando-se pais - A adoção em todos os seus passos. São Paulo, SP: Casa do Psicólogo.

Mahajan, A.P; Sayles, J.N; Patel, V.A; Remien, R.H; Ortiz, D; Szekeres,G; Coates, T.J (2008). Stigma in the HIV/aids epidemic: a review of the literature and recommendations for the way forward. National Institute of Health (NIH), 22(Suppl 2), 67-79. http://dx.doi.org/10.1097/01.aids.0000327438.13291.62

Maldonado, M.T. (1995) Os caminhos do coração: pais e filhos adotivos. São Paulo: Saraiva.

Marques, H.H.S; Silva, N.G.; Gutierrez, P.L.; Lacerda, R.;Ayres, J.R.C.M; DellaNegra, M.; França Jr., I.; Galano, E.; Paiva, V; Segurado, A.A.C; Silva, M.H. (2006). A revelação do diagnóstico na perspectiva dos adolescentes vivendo com HIV/AIDS e seus pais e cuidadores. Cadernos de Saúde Pública, 22(3), 619-629. http://dx.doi.org/10.1590/S0102-311X2006000300017

Mignoli, C.Q., Rafael, E.C., \& Medeiros, P.C. (2010). O serviço social frente à questão dos direitos e da adoção de crianças e adolescentes portadores do vírus HIV. Anais do fórum de iniciação científica da FUNEC, 1(1).

Minayo, M.C.S. (1994) Ciência, Técnica e Arte: O desafio da Pesquisa Social. In: Minayo, M.C.S et al. Pesquisa Social: teoria, método e criatividade. 23 ed, Petrópolis: Vozes.

Miranda, C.E.S., \& Cohen, R.H.P. (2012). Uma Criança é Adotada: O Lugar Simbólico da Filiação e seus Efeitos Subjetivos. Psicologia em Pesquisa, 6(1), 61-67. Disponível em: $\quad$ http://pepsic.bvsalud.org/scielo.php?script=sci_arttext\&pid=S1982$12472012000100008 \& \operatorname{lng}=$ pt\&tlng $=$ pt. 
Ogden, J; Nyblade, L. (2005). Common at its core: HIV-related stigma across contexts. International Center for Research on women (ICRW). Disponível em: https://n2r4h9b5.stackpathcdn.com/wp-content/uploads/2016/10/Common-at-itsCore-HIV-Related-Stigma-Across-Contexts.pdf

Oliveira, H.F.(2014) Adoção - Aspectos jurídicos, práticos e efetivos: doutrina, modelos práticos e jurisprudência. São Paulo: Mundo Jurídico Editora.

Oliveira, P.A.B.A.; Souto, J.B.; Silva Júnior, E.G. (2017). Adoção e Psicanálise : a Escuta do Desejo de Filiação. Psicologia: Ciência e Profissão, 37(4), 909-922. https://doi.org/10.1590/1982-3703003672016

Oliveira, R.N; Takahashi, R.F. (2011) As práticas de saúde para redução da transmissão vertical do HIV em unidades de atenção básica: realidades e determinantes. Saúde Coletiva, 8 (54), 234-238. Retirado de: www.redalyc.org/articulo.oa?id=84221108003

Parker, R, Aggelton, P (2003). HIV and aids-related stigma and discrimination: a conceptual framework and implications for action. Social Science \& Medicine, 57(1), 53-54. https://doi.org/10.1016/S0277-9536(02)00304-0

Reidpath, D.D \& Chan, K.y (2005) HIV discrimination: integrating the results from a six country situational analysis in the Asia Pacific. Aids Care, Suppl 2, 195-204. https://doi.org/10.1080/09540120500120278

Reppold, C. T. \& Hutz, C. S. (2003). Reflexão social, controle percebido e motivações à adoção: características psicossociais das mães adotivas. Estudos de Psicologia, 8(1), 25-36. http://dx.doi.org/10.1590/S1413-294X2003000100004.

Sadala, M.L.A \& Marques, S.A (2006). Vinte anos de assistência a pessoas com HIV/aids no Brasil: a perspectiva de profissionais de saúde. Cadernos de Saúde Pública, 22(11), p. 2369-78. http://dx.doi.org/10.1590/S0102-311X2006001100011

Santos, S.D.M (2010) Um novo olhar sobre o conceito de abandono de crianças. Acta Scientiarum Human and Social Sciences, Maringá, 32(1), 6372. https://doi.org/10.4025/actascihumansoc.v32i1.7210

Shetty,A.K \& Powell, G.(2003) Children Orphaned by aids: a global perspective. Seminars in Pediatric Infectious Diseases, 14(1), 25-31. https://doi.org/10.1053/spid.2003.127214

Silva, F., \& Cavalcante, L. (2012). Fatores de risco e proteção para crianças soropositiva ao HIV. Diaphora, 12(1), 48-57.

Silva, J.A (2010) Adoção de crianças maiores: percepções e vivências dos adotados. Psicologia em Revista, Belo Horizonte, 16(2), 434-436. Disponível em: http://periodicos.pucminas.br/index.php/psicologiaemrevista/issue/view/154

Silva, M.R., Alvarenga, W.A., Dupas, G. (2014) Experiência do cuidador no tratamento preventivo da criança exposta ao Vírus da Imunodeficiência Humana. Revista da Rede de Enfermagem do Nordeste, 15(5), 743-52. http://dx.doi.org/10.15253/rev\%20rene.v15i5.3232

Silveira, A.M. (2005). Adoção de crianças negras: inclusão ou exclusão? São Paulo: Veras Editora.

Siqueira, A.C. (2012). A garantia ao direito à convivência familiar e comunitária em foco. Estudos de Psicologia (Campinas), 29(3), 437-444. https://dx.doi.org/10.1590/S0103166X2012000300013 
Souza, H.P. (2012) Adoção Tardia - Devolução ou Desistência de um Filho. A Necessária Preparação para Adoção. Curitiba: Juruá Editora.

Souza, H.P, Casanova, R.P.S. (2014) Adoção e a preparação dos pretendentes: roteiro para trabalho nos grupos preparatórios. Curitiba: Jurua Editora.

Uziel, A.P.(2007) Homossexualidade e adoção. Rio de Janeiro: Garamond.

Valério, T.A.M, \& Lyra, M. C.D.P. (2014). A construção cultural de significados sobre adoção: um processo semiótico. Psicologia \& Sociedade, 26(3), 716725. https://dx.doi.org/10.1590/S0102-71822014000300020

Weber, L.N.D. (2004). O psicólogo e as práticas de adoção. In: Brandão, E.P.; Gonçalves, H.S. Psicologia jurídica no Brasil. Rio de Janeiro: Nau, 99-140.

Weiss, M.G; Ramakrishna, J. (2006) Stigma interventions and research for international health, Lancet, 367, 536-38. https://doi.org/10.1016/S0140-6736(06)68189-0

Yamaoka, M. W. (2009). Grupo de estudos e apoio à adoção de São Bernardo do Campo. Periódico sobre adoção do GEAA-SBC, (8-9), 15-18.

Yarney, L., Mba, C., Asampong, E. (2015) Qualitative study on the socio-cultural determinants of care of children orphaned by AIDS in the Ashanti and Eastern regions of Ghana. BMC Public Health, 15(6),1-13. https://doi.org/10.1186/s12889-014-13327

Zucchi, E.M; Barros, C.R.S; Paiva, V.S.F; França Junior, I (2010) Estigma e discriminação vividos na escola por crianças e jovens órfãos por aids. Educação $e$ Pesquisa, São Paulo, 36(3), 719-34. http://dx.doi.org/10.1590/S151797022010000300005 